\title{
Simulation of the Reduction Process of Solid Oxide Fuel Cell Composite Anode Based on Phase Field Method
}

\author{
Zhenjun Jiao $^{a, b}$, Naoki Shikazono ${ }^{a, b}$ \\ a. Institute of Industrial Science, the University of Tokyo 4-6-1 Komaba, Meguro-ku, Tokyo \\ 153-8505, Japan \\ b.CREST, JST, 4-6-1 Komaba, Meguro-ku, Tokyo 153-8505, Japan
}

\begin{abstract}
It is known that the reduction process influences the initial performances and durability of nickel-yttria-stabilized zirconia composite anode of the solid oxide fuel cell. In the present study, the reduction process of nickel-yttria stabilized zirconia composite anode is simulated based on the phase field method. An three-dimensional reconstructed microstructure of nickel oxide-yttria stabilized zirconia composite obtained by focused ion beam-scanning electron microscopy is used as the initial microstructure for the simulation. Both reduction of nickel oxide and nickel sintering mechanisms are considered in the model. The reduction rates of nickel oxide at different interfaces are defined based on the literature data. Simulation results are qualitatively compared to the experimental anode microstructures with different reduction temperatures.

Keywords: SOFC, Reduction, Sintering, Phase field method, Anode
\end{abstract}

\section{Introduction}

With a high energy conversion efficiency and fuel flexibility, solid oxide fuel cell (SOFC, hereafter) has been attracting increasing attentions in recent decades $[1,2]$, while reliability and long time stability of the electrodes remain as the main challenges. It has been reported that nickel (Ni, herefter) agglom-

Email address: zhenjun@iis.u-tokyo.ac.jp (Naoki Shikazono ${ }^{a, b}$ )

Preprint submitted to Elsevier

November 16, 2015

(C) 2015. This manuscript version is made available under the Elsevier user license http://www.elsevier.com/open-access/userlicense/1.0/ 
eration, which results in the decrease of active three phase boundary (TPB, hereafter) density and Ni network connectivity, is one of the main causes for anode degradation $[3,4,5,6,7,8,9,10,11,12]$. It is thus very important to optimize the microstructure which has both high initial performance and long time durability. Manufacturing processes, screen-printing, sintering and reduction etc., are of great importance to improve the microstructure of the anode. Plascencia \& Utigard [13] and Utigard et al. [14] have studied the reduction process of $\mathrm{NiO}$ particles at different temperatures. It is shown that different initial reduction temperatures lead to totally different morphologies of Ni particles, which may influence the initial performance and durability of the composite anode. At a temperatures above $600{ }^{\circ} \mathrm{C}, \mathrm{Ni}$ particle agglomeration and sintering were also found to take place in the reduction process. Jiao et al. [15] have investigated the effects of reduction temperature on the initial performances and short-time durability of the Ni-YSZ composite anodes. It is found that the reduction temperatures largely influence the initial anode performance and durability. Anode reduced at $500{ }^{\circ} \mathrm{C}$ showed very poor initial performance and durability, while a higher reduction temperature leads to a better anode initial performance and durability. Jeangros et al. $[16,17]$ have observed $\mathrm{NiO}$ reduction process of NiO-YSZ composite anode in-situ using an environmental transmission-electron-microscopy at low temperature. It is reported that the reduction of $\mathrm{NiO}$ starts from at NiO-YSZ interface at $380{ }^{\circ} \mathrm{C}$ and in very low hydrogen pressure. The Ni particle agglomeration and sintering were also found to take place in the reduction process around a temperatures of $400{ }^{\circ} \mathrm{C}$. Zhu et. al. [18] have reported that the initial microstructure of $\mathrm{Ni}$-YSZ and the corresponding performances can be influenced by the reducing and sintering processes of $\mathrm{NiO}$ to $\mathrm{Ni}$. The reduction process starts from grain surface or grain boundary with relatively low binding energy. Chen et al. and Jiao et al. [20, 21] used phase field method (PFM, hereafter) to simulate the microstructural evolution of Ni-YSZ anode using 3D focused ion beam-scanning electron microscopy (FIB-SEM, heareafter) reconstruction microstructure of NiYSZ anode. Li et al. and Jiao et al. [22, 23] have applied PFM to simulate both 
the morphological and crystal structural evolutions of Ni-YSZ anode during the sintering process. Besides phase field method, the sintering analysis of Ni phase was also conducted using Kinetic Monte Carlo simulation, which was verified by FIB-SEM reconstruction by Hara et al. [24].

Before initial operation, calcined NiO-YSZ composite is reduced to Ni-YSZ which functions as the anode. Reduced Ni is concurrently sintered during this process, which is a very complex phenomenon and its mechanism is not fully understood. In this study, a numerical model based on PFM is proposed to simulate the reduction process of composite NiO-YSZ anode to study the influences of reduction process on the initial Ni-YSZ anode microstructure right after calcination. Both volume change and sintering mechanisms are combined in the model to investigate the microstructure evolution during the reduction process.

\section{Experimental}

Cell preparation - The anode cermet powder was prepared by mechanically mixing $\mathrm{NiO}$ and YSZ powders (AGC Seimi Chem. Corp., Japan), where the volume ratio of $\mathrm{NiO}$ to $\mathrm{YSZ}$ was $60 \%: 40 \%$. The anode was then sintered at $1450{ }^{\circ} \mathrm{C}$ for 3 hours. Details of the fabrication process have been introduced in Refs. [15, 19].

Microstructure analysis - The porous sample was analyzed by FIB-SEM (Carl Zeiss, NVision 40) in this study. The porous sample was first infiltrated by low viscosity epoxy resin under low pressure atmosphere (ca. $15 \mathrm{~Pa}$ ), so that the pores of the porous electrode could be easily distinguished during FIB-SEM observation. The sample was then polished by using Ar-ion beam cross-section polisher (JEOL Ltd., SM-09010). The 3D microstructure of NiO-YSZ anode then can be virtually reconstructed based on a series of 2D images by Matlab 
and Avizo, as shown in Fig. 1. The details of dual-beam FIB-SEM observation technique are also introduced in Refs. [15, 19].

Anode reduction - Three anodes were reduced at $500{ }^{\circ} \mathrm{C}, 800{ }^{\circ} \mathrm{C}$ and $1000{ }^{\circ} \mathrm{C}$ for 90 minutes, 30 minutes and 10 minutes, respectively, to ensure a complete reduction [15]. The microstructures of anodes after reduction were then analyzed by FIB-SEM.

\section{Simulation Modeling}

The simulation procedures are illustrated by the flow diagram shown in Fig. 2. Different phases were presented by different colors. In Step 1, the original microstructure of NiO-YSZ anode was reconstructed based on a series of FIBSEM images. The simulation then starts by converting finite thickness of $\mathrm{NiO}$ phase to Ni phase at NiO-pore and NiO-YSZ interfaces, which is demonstrated as Interval 1 in Fig. 2. The corresponding time step $\Delta t$ of this $\mathrm{NiO}$ to $\mathrm{Ni}$ conversion is estimated by an reduction rate kinetic model proposed by Utigard et al. [14]. The details are described below. After this $\mathrm{NiO}$ to Ni conversion, 40 vol\% of newly generated $\mathrm{Ni}$ were randomly deleted and converted to pores of a characteristic size $s$ in Interval 2 to ensure the volume decrease of $\mathrm{NiO}$ reduction process [1]. In Interval 3, Ni sintering simulation based on PFM is conducted for a characteristic time step $\Delta t$. Subsequently, based on the microstructure shown in Step 4, $\mathrm{NiO}$ of finite thickness at $\mathrm{NiO}$-pore and $\mathrm{NiO}-\mathrm{Ni}$ interfaces are converted to $\mathrm{Ni}$ phase in Interval 4, similarly as in Interval 1. Finally, Steps 3 to 5 are repeated until all $\mathrm{NiO}$ had been converted into Ni. In order to simplify the model, reduction rate along the Ni grain boundary is not considered in this study.

Utigard et al. [14] has proposed a reduction rate model based on chemical kinetics at the reaction front of $\mathrm{NiO}$ particles, which is given by the following 
equation,

$$
\frac{\mathrm{d} X}{\mathrm{~d} t}=k(1-X)^{\frac{2}{3}}
$$

where $X$ is the volume ratio of the reduced $\mathrm{NiO}$ to the original $\mathrm{NiO}$, and $k$ is the reduction rate constant. Based on this equation, we can obtain an equation for the reduction time as a function of reduced $\mathrm{NiO}$ volume ratio $X$

$$
t=\frac{3}{k}\left[(X-1)^{\frac{1}{3}}+1\right] .
$$

The value of $k$ in this study was estimated to be $0.2 \mathrm{~min}^{-1}$ based on our previous work [23]. It was found that the above relation was valid throughout the reduction process except the initial stage. The rate at the initial reduction stage was slightly larger than the predicted value. This can be attributed to the larger reduction rates at $\mathrm{NiO}$-pore and $\mathrm{NiO}-\mathrm{YSZ}$ interfaces than that of $\mathrm{NiO}-\mathrm{Ni}$ interface, where newly reduced $\mathrm{Ni}$ layer prohibits gas diffusion. In the present study, the ratio of reduction rates at $\mathrm{NiO}-$ pore, $\mathrm{NiO}-\mathrm{YSZ}$ and $\mathrm{NiO}-\mathrm{Ni}$ were set as $1: 1: 0.4$. From the volume change of $\mathrm{NiO}$ during Interval 2 , the physical time step $\Delta t$ can be calculated from Eq. (2).

Phase field method is applied to quantitatively simulate the sintering process of $\mathrm{Ni}$ in this study. In addition to the Ni phase morphological change, $\mathrm{Ni}$ crystallographic orientation and crystal grain growth were also considered in the simulation. In the present study, only the sintering of $\mathrm{Ni}$ phase is considered, and $\mathrm{NiO}$ and YSZ phases are treated as a immobile phases. Two order parameters (OPs, hereafter), $C^{\mathrm{Ni}}(\mathbf{r})$ and $C^{\text {Oxide }}(\mathbf{r})$ are introduced in this study. $C^{\text {Oxide }}(\mathbf{r})$ is defined to represent the combination of $\mathrm{NiO}$ and YSZ phases. Inside the Ni phase, $C^{\mathrm{Ni}}(\mathbf{r})=1$ and $C^{\text {Oxide }}(\mathbf{r})=0$. Inside the NiO and YSZ phases, $C^{\mathrm{Ni}}(\mathbf{r})=0$ and $C^{\text {Oxide }}(\mathbf{r})=1$. The pore phase is defined as $C^{\text {pore }}(\mathbf{r})=1-C^{\mathrm{Ni}}(\mathbf{r})-C^{\text {Oxide }}(\mathbf{r})$. At the interfaces between the phases, the OP transits smoothly from 0.0 to 1.0. The physical interface can be defined by tracking $\mathrm{OPs}=0.5$. In order to simulate the phase and crystal grain evolutions at the same time, grain crystallographic orientation OPs $\left[\eta_{1}(\mathbf{r}), \eta_{2}(\mathbf{r}), \ldots, \eta_{p}(\mathbf{r})\right]=( \pm 1,0, \ldots, 0),(0, \pm 1, \ldots, 0), \cdots(0,0, \ldots, \pm 1)$, 
are introduced within the corresponding phases in space, while $p$ is the corresponding crystallographic orientation numbers of the phase. The non-conserved orientation OP $\eta$ transits smoothly from -1 to 1 at the interface of any two adjacent grains, while \pm 1 indicate the opposite crystal orientations. At the grain boundary between any two grains with different orientations, $\eta$ has its absolute value transient between 0.0 and 1.0. All orientation OPs are zero for the pore phase. In order to obtain the crystallographic orientations of the newly converted $\mathrm{Ni}$ phase, a disordered orientation is randomly assigned, i.e., randomly distributed values $( \pm 0.001)$ are given for the all voxels. The way to obtain the initial crystallographic orientations of $\mathrm{NiO}$ and $\mathrm{YSZ}$ phases has been introduced in Ref. [23]. According to the capability of the computer, the number of $\mathrm{Ni}$ crystallographic orientation was set at 15 .

The total free energy of the three phase composition and orientation OPs thus can be constructed within the diffuse-interface field theory as [22, 23]

$$
F=\int_{V} d V\left[\begin{array}{l}
f_{0}\left(C^{\mathrm{Ni}}, C^{\text {Oxide }} ; \eta_{i}^{\mathrm{Ni}}, \eta_{i}^{\text {Oxide }}\right)+\frac{\kappa_{C}^{\mathrm{Ni}}}{2}\left(\nabla C^{\mathrm{Ni}}\right)^{2}+\frac{\kappa_{C}^{\text {Oxide }}}{2}\left(\nabla C^{\text {Oxide }}\right)^{2} \\
+\sum_{i=1}^{p} \frac{\kappa_{i}^{\mathrm{Ni}}}{2}\left(\nabla \eta_{i}^{\mathrm{Ni}}\right)^{2}+\sum_{i=1}^{q} \frac{\kappa_{i}^{\text {Oxide }}}{2}\left(\nabla \eta_{i}^{\text {Oxide }}\right)^{2}
\end{array}\right],
$$

where $\kappa_{C}^{\mathrm{Ni}}, \kappa_{C}^{\text {Oxide }}$ and $\kappa_{i}^{\mathrm{Ni}}, \kappa_{i}^{\text {Oxide }}$ are the corresponding gradient energy coefficients and $f_{0}$ is the local free energy density which is given by

$$
\begin{aligned}
& f_{0}=f_{1}\left(C^{\mathrm{Ni}}\right)+f_{1}\left(C^{\text {Oxide }}\right)+\sum_{i=1}^{p} f_{2}\left(C^{\mathrm{Ni}}, \eta_{i}^{\mathrm{Ni}}\right)+\sum_{i=1}^{q} f_{2}\left(C^{\text {Oxide }}, \eta_{i}^{\text {Oxide }}\right) \\
& +\sum_{i=1}^{p} \sum_{j \neq i}^{p} f_{3}\left(\eta_{i}^{\mathrm{Ni}}, \eta_{j}^{\mathrm{Ni}}\right)+\sum_{i=1}^{q} \sum_{j \neq i}^{q} f_{3}\left(\eta_{i}^{\text {Oxide }}, \eta_{j}^{\text {Oxide }}\right)+f_{4}\left(C^{\mathrm{Ni}}, C^{\text {Oxide }}\right)
\end{aligned}
$$

where

$$
\left\{\begin{array}{l}
f_{1}(C)=-(A / 2)\left(C-C^{m}\right)^{2}+(B / 4)\left(C-C^{m}\right)^{4}+(D / 4)\left(C-C^{0}\right)^{4} \\
f_{2}\left(C, \eta_{i}\right)=-(\gamma / 2)\left(C-C^{0}\right)^{2}\left(\eta_{i}\right)^{2}+(\gamma / 4)\left(\eta_{i}\right)^{4} \\
f_{3}\left(\eta_{i}, \eta_{j}\right)=\left(\varepsilon_{i j} / 2\right)\left(\eta_{i}\right)^{2}\left(\eta_{j}\right)^{2} \\
f_{4}\left(C^{x}, C^{y}\right)=(\lambda / 2)\left(C^{x}\right)^{2}\left(C^{y}\right)^{2}
\end{array}\right.
$$

The phenomenological parameters in Eq. (5) are assumed as $C^{m}=0.5, C^{0}=$ $0.0, A=1.0, B=4.0, D=1.0, \gamma=1.0, \varepsilon_{i j}=3.0$ and $\lambda=1.0$ [23]. These 
coefficients are chosen so that $f_{0}$ has degenerate minima to prohibit the interdiffusion between different phases and grains. This forces each point in space to belong to a single phase with the given grain orientation. Based on the standard Cahn-Hilliard dynamics evolution equation, the conserved governing equation of Ni volume fraction coarsening evolution can be obtained as

$$
\left\{\begin{array}{l}
\frac{\partial C^{\mathrm{Ni}}}{\partial t}=\nabla \cdot\left\{M_{C}^{\mathrm{Ni}} \nabla\left[\frac{\partial f_{0}}{\partial C^{\mathrm{Ni}}}-\kappa_{C}^{\mathrm{Ni}} \nabla^{2} C^{\mathrm{Ni}}\right]\right\} \\
\frac{\partial C^{\text {Oxide }}}{\partial t}=\nabla \cdot\left\{M_{C}^{\text {Oxide }} \nabla\left[\frac{\partial f_{0}}{\partial C^{\text {Oxide }}}-\kappa_{C}^{\text {Oxide }} \nabla^{2} C^{\text {Oxide }}\right]\right\}
\end{array},\right.
$$

where $t$ is time and $M_{C}$ is the material mobility in the corresponding anode operation condition. In the present study, mobility of the oxide phase is set as $M_{C}^{\text {Oxide }}=0$ since $\mathrm{NiO}$ and YSZ phases are assumed to be immobile.

Based on the standard Allen-Cahn dynamics evolution equation, the nonconserved governing equation of solid crystal grain growth can be obtained as

$$
\left\{\begin{array}{l}
\frac{\partial \eta_{i}^{\mathrm{Ni}}}{\partial t}=-L_{i}^{\mathrm{Ni}}\left[\frac{\partial f_{0}}{\partial \eta_{i}^{\mathrm{Ni}}}-\kappa_{i}^{\mathrm{Ni}} \nabla^{2} \eta_{i}^{\mathrm{Ni}}\right] ; i=1,2, \ldots, p \\
\frac{\partial \eta_{i}^{\text {Oxide }}}{\partial t}=-L_{i}^{\text {Oxide }}\left[\frac{\partial f_{0}}{\partial \eta_{i}^{\text {Oxide }}}-\kappa_{i}^{\text {Oxide }} \nabla^{2} \eta_{i}^{\text {Oxide }}\right] ; i=1,2, \ldots, q
\end{array},\right.
$$

where $L_{i}$ are the coefficients of $\mathrm{Ni}$ grain boundary mobilities according to different orientations in the specific phase and $L_{i}^{\text {Oxide }}=0$. The gradient coefficients ratios for phase parameters are set as $\kappa_{C}^{\mathrm{Ni}}: \kappa_{C}^{\text {Oxide }}: \kappa_{i}^{\mathrm{Ni}}: \kappa_{i}^{\text {Oxide }}=1: 0.82$ : $0.71: 0.52$, where $\kappa_{C}^{\mathrm{Ni}}=1.0$ is used for the reference calculation [23].

Wazzan [25] investigated the lattice and grain boundary diffusions in Ni. It is found that the ratio of the grain boundary diffusion coefficient to the lattice diffusion coefficient varies from $10^{10}$ to $10^{3}$ in a temperature range of $748^{\circ} \mathrm{C}$ to $1373^{\circ} \mathrm{C}$, which suggests that grain boundary diffusion dominates the sintering of Ni. In this study, the bulk lattice diffusion of Ni thus is neglected. Then, the mobility of $\mathrm{Ni}$ is described as

$$
M_{C}^{\mathrm{Ni}}=M_{\mathrm{Ni}-\mathrm{GB}}\left(1-\sum_{1}^{p} \eta_{\mathrm{Ni}}^{2}\right) g\left(1-C^{\text {Oxide }}\right),
$$

where $M_{\mathrm{Ni}-\mathrm{GB}}$ is the $\mathrm{Ni}$ grain boundary mobility in the phase field modeling. Function $g(x)=x^{6}\left(10 x^{2}-15 x+6\right)$ is used to ensure that Ni phase is immobile at Ni-YSZ and Ni-NiO interfaces by limiting Ni mobility transiently ranging 
from the bulk value of $M_{\mathrm{Ni}-\mathrm{GB}}$ at $C^{\text {Oxide }}=0.5$ to 0.0 at $C^{\text {Oxide }}=1.0$.

\section{Numerical Procedure}

In the present simulation, cubic $256 \times 256 \times 256$ discrete voxels were used to describe the initial 3D NiO-YSZ structure with a size of $3.76 \mu \mathrm{m} \times 3.76 \mu \mathrm{m} \times 3.76 \mu \mathrm{m}$ as shown in Fig. 1 (b), while $l_{0}=14.7 \mathrm{~nm}$ is the voxel size. The characteristic reduction lengths at $\mathrm{NiO}$-pore and $\mathrm{NiO}$-YSZ interfaces were set as $73.5 \mathrm{~nm}$, and at $\mathrm{NiO}-\mathrm{Ni}$ interface as $29.4 \mathrm{~nm}$ for Intervals 1 and 4 as shown in Fig. 2. The volume change of $\mathrm{NiO}$ before and after $\mathrm{NiO}$ to $\mathrm{Ni}$ conversion during Intervals 1 and 4 can be calculated based on the characteristic reduction lengths. The corresponding $\mathrm{Ni}$ sintering characteristic time step $\Delta t$ during interval 3 can be obtained from Eq. (2). After every $\mathrm{NiO}$ to $\mathrm{Ni}$ conversion during Intervals 1 and 4, 40 vol\% of newly generated $\mathrm{Ni}$ were randomly converted to pores with a characteristic length $s=l_{0}$. In other words, $40 \%$ of the voxels converted to $\mathrm{Ni}$ from $\mathrm{NiO}$ after Intervals 1 and 4 are randomly replaced by a pore phase of voxel size. In the future study, the characteristic length $s$ and the shape of the newly generated inner pore should also be investigated to study their influences on the simulation results.

In order to facilitate the simulation of $\mathrm{Ni}$ sintering, $\mathrm{Ni}$ material mobility was non-dimensionalized as $M_{C}^{\mathrm{Ni} *}=\left(1-\sum_{1}^{p} \eta_{\mathrm{Ni}^{2}}{ }^{2}\right) g\left(1-C^{\text {Oxide }}\right)$ and dimensionless interval time for $\mathrm{Ni}$ sintering can be obtained as $\Delta t^{*}=M_{\mathrm{Ni}-\mathrm{GB}} \Delta t / l_{0}^{2}$. It has been estimated that $M_{\mathrm{Ni}-\mathrm{GB}} \approx 3.8 \times 10^{-19} \mathrm{~m}^{2} \mathrm{~s}^{-1}$ gives reasonable result, with a phase field diffusive width of $W=58.8 \mathrm{~nm}$, at the temperature of $800^{\circ} \mathrm{C}$ [23]. The Ni grain boundary mobilities are non-dimensionalized as $L_{i}^{\mathrm{Ni} *}=L_{i}^{\mathrm{Ni}} l_{0}^{2} / M_{\mathrm{Ni}-\mathrm{GB}}$ and set $L_{i}^{\mathrm{Ni} *}=1$. The non-dimensional mobilities of the oxide phases are set to zero, $M_{C}^{\text {Oxide* }}=L_{i}^{\text {Oxide* }}=0$ as described previously. The time step used in the sintering simulation is set as $d t^{*}=0.05$ to ensure the stability of the computation. The iteration number $N$ used in the simulation of 
sintering process thus can be obtained as $N=\Delta t^{*} / d t^{*}$. Because of the usage of Fourier-spectral approximation method in solving the governing equations, direct periodic boundary conditions was applied along the three axes [23].

\section{Results and Discussions}

For the simulation results, 3D and cross-sectional images during the reduction process at four typical dimensionless time are shown in Fig. 3. The corresponding physical time durations are 1.5, 11.8, 36.8 and 303.3 minutes, respectively. The volume decrease of $\mathrm{NiO}$ to $\mathrm{Ni}$ and the sintering of $\mathrm{Ni}$ phase can be seen in the simulation results. The decrease in volume leads to the formation of inner pores. The sintering of Ni phase and the growing of Ni grains together determine the final morphology of Ni-YSZ anode microstructure. Dimensionless time of $t^{*}=32.0$ was defined as the termination time of the simulation including both reduction process and short-time sintering.

Figure 4 shows the 2D SEM images of the Ni-YSZ anode right after complete reduction at different temperatures of $500{ }^{\circ} \mathrm{C}, 800{ }^{\circ} \mathrm{C}$ and $1000{ }^{\circ} \mathrm{C}$, respectively. White, gray and black regions correspond to $\mathrm{Ni}$, YSZ and pore phases, respectively [15]. When the anode is reduced at $500{ }^{\circ} \mathrm{C}$, large amount of uniformly distributed nano-scale inner pores can be observed in the Ni phase. Ni particles nearly keep the peripheral original shapes of $\mathrm{NiO}$ particles before reduction. The $40 \%$ volume decrease during the $\mathrm{NiO}$ to $\mathrm{Ni}$ conversion was achieved by the formation of large amount of inner pores inside the Ni phase. For the anodes reduced at $800{ }^{\circ} \mathrm{C}$ and $1000{ }^{\circ} \mathrm{C}$, relatively dense Ni particles with less inner pores can be observed after the reduction process. The volume reduction was achieved by the densification of the $\mathrm{Ni}$ phase caused by sintering. It is seen that reduction temperature obviously influences the initial anode microstructure by influencing $\mathrm{Ni}$ sintering [15]. The competition between reduction and sintering mechanisms finally determines the anode microstructure. When sintering 
is slow, reduced $\mathrm{Ni}$ keeps the original $\mathrm{NiO}$ particle shape with large amount of inner pores to achieve volume reduction. If sintering is effectively fast, the morphology of reduced $\mathrm{Ni}$ can be largely modified compared to the original $\mathrm{NiO}$ particles.

It is well known that the microstructures with length scales below the diffusing interface thickness, i.e. phase field diffusive width, can be smoothed out in the PFM simulation. By changing the phase field diffusive width, the physical effective thickness of mobile Ni layer can be changed so that sintering rate in the PFM simulation can be changed, without changing the value of $\mathrm{Ni}$ grain boundary mobility. The phase field diffusive width utilized in the above sintering simulations is 4 voxels, which is approximately $58.8 \mathrm{~nm}$. It is known that the phase field diffusive width is proportional to the square root of the ratio of phase gradient energy coefficient $\kappa$ to the local free energy density $f_{0}$ coefficient which stands for the barrier height of the double-well potential at interface[20]. In order to verify the effect of phase field diffusive width $W$, the phase gradient energy coefficient $\kappa_{C}^{\mathrm{Ni}}$ varied as $\kappa_{C}^{\mathrm{Ni}}=0.25$ and 4.0. $\kappa_{C}^{\mathrm{Ni}}=0.25$ corresponds to the phase field diffusive width of approximately $29.4 \mathrm{~nm}$, and $\kappa_{C}^{\mathrm{Ni}}=4.0$ corresponds to approximately $117.6 \mathrm{~nm}$. Figure 5 shows the 3D model predictions and cross-sectional images of PFM simulation results at $t^{*}=32.0$ with different values of the gradient energy coefficients $\kappa_{C}^{\mathrm{Ni}}$. It is seen that with a half phase field diffusive width, the sintering of $\mathrm{Ni}$ and the growth of $\mathrm{Ni}$ grain boundary were suppressed, while large amount of small inner pores were formed. With a double phase field diffusive width, the sintering of $\mathrm{Ni}$ and the growth of $\mathrm{Ni}$ grain boundary were enhanced, while less and larger size inner pores can be observed compared to the results with reference phase field diffusive width of $W=58.8 \mathrm{~nm}\left(\kappa_{C}^{\mathrm{Ni}}=1.0\right)$. Figure 6 shows the $2 \mathrm{D}$ cross-sectional images of anode crystal microstructure corresponding to three different phase field diffusive widths. It is seen that Ni grain growth shows the same tendency as the Ni phase. A smaller phase field diffusive width leads to limited grain boundary sintering and smaller grain size, while larger one leads to enhanced grain boundary sin- 
tering and larger grain size.

In this paper, a methodology for predicting reduction process is introduced. However, the simulation results of the anode microstructure after reduction were not quantitatively compared to the experimental results. In the future investigation, the simulation result will be validated by the experimental microstructure analysis. The influences of reduction conditions on model parameters will be quantitatively investigated. In addition, the resolution of 3D reconstruction should also be increased in order to validate the simulation results with different reduction rates of different interfaces.

\section{Conclusion}

A model based on PFM has been proposed to simulate the reduction process of $\mathrm{NiO}$ in the SOFC composite anode. In addition to the simulation of reduced $\mathrm{Ni}$ volume during reduction, $\mathrm{Ni}$ phase evolution caused by sintering is considered. Crystallographic orientations are also introduced in the model to simulate the corresponding crystal grain growth. It is demonstrated that it is possible to mimic the effect of reduction temperature by changing the phase field diffusive width. It is seen from the simulation result that smaller phase field diffusive width leads to limited grain boundary sintering and smaller grain size, while larger phase field diffusive width leads to enhanced grain boundary sintering and larger grain size.

\section{Acknowledgments}

This work was partly supported by the Core Research for Evolution Science and Technology (CREST), JST. 


\section{Reference \\ References}

[1] C. S. Subhash and K. Kevin, High Temperature Solid Oxide Fuel Cells: Fundamentals, Design and Applications, Elsevier Advanced Technology, (2003).

[2] S. Primdahl, Ph.D. Thesis, Riso National Laboratory for Sustainable Energy, Technical University of Denmark, Denmark., (1999).

[3] L. Holzer, B. Munch, B. Iwanschitz, M. Cantoni, T. Hocker and T. Graule, J. Power Sources, 196, 7076-7089 (2011).

[4] H-Y. Chen, H-C. Yu, J. S. Cronin, J. R. Wilson, S. A. Barnett and K. Thornton, J. Power Sources, 196, 1333-1337 (2011).

[5] S. P. S. Badwal and M. J. Bannister and R. H. J. Hannink, Science and Technology of Zirconia V, Technomic publishing Company, (2003).

[6] S. Koch and P. V. Hendriksen, M. Mogensen, Y-L. Liu, N. Dekker, B. Rietveld, B. De. Haart and F. Tietz, Fuel Cells, 2, 130-136 (2006).

[7] T. Matsui, J-Y. Kim, R. Kishida and K. Eguchi, Electrochemistry, 77, 123-126 (2009).

[8] B. de Boer, Ph.D. Thesis, University of Twente, the Netherlands, (1998).

[9] J. Mizusaki, H. Tagawa, T. Saito, T. Yamamura, K. Kamitani, K. Hirano, S. Ehara, T. Takagi, T. Hikita, M. Ippommatsu, S. Nakagawa and K. Hashimoto, Solid State Ionics, 70-71, 52-58 (1994).

[10] J. Mizusaki, H. Tagawa, T. Saito, T. Yamamura, K. Kamitani, K. Hirano, S. Ehara, T. Takagi, T. Hikita, M. Ippommatsu, S. Nakagawa and K. Hashimoto, J. Electrochem. Soc., 141, 2129-2134 (1994).

[11] M. S. Schmidt, K. V. Hansen, K. Norrman and M. Mogensen, Solid State Ionics, 180, 431-438 (2009). 
[12] D. Simwonis and F. Tietz and D. Stover, Solid State Ionics, 132, 241-251 (2000).

[13] G. Plascencia and T. Utigard, Chem. Eng. Sci., 64, 3879-3888 (2009).

[14] T. Utigard, M. Wu, G. Plascencia and T. Marin, Chem. Eng. Sci., 60, 2061-2068 (2005).

[15] Z. Jiao and N. Shikazono, J. Electrochem. Soc., 162(6), F571-F578 (2015).

[16] Q. Jeangros, T. W. Hansen, J. B. Wagner, C. D. Damsgaard, R. E. DuninBorkowski, C. Hebert and J. Van herle and A. Hessler-Wyser, J. Mater. Sci., 48, 2893-2907 (2012).

[17] Q. Jeangros, A. Faes, J. B. Wagner, T. W. Hansen, U. Aschauer, J. Van herle, A. Hessler-Wyser and R. E. Dunin-Borkowski, Acta. Materialia., 58, 4578-4589 (2010).

[18] X. Zhu, C. Guan, Z. Lu and W. Su, J. Electrochem. Soc., 160, F1170-F1174 (2013).

[19] Z. Jiao, N. Shikazono and N. Kasagi, J. Power Sources, 24, 8019-8027 (2010).

[20] H.-Y. Chen, H.-C. Yu, J. S. Croninb, J. R. Wilsonb, S. A. Barnett and K. Thornton, J. Power Sources, 196, 1333-1337 (2011),

[21] Z. Jiao and N. Shikazono, J. Electrochem. Soc., 160, F709-F715 (2013).

[22] Q. Li, L. Y. Liang, K. Gerdes and L.-Q. Chen, Appl. Phys. Lett., 101, 033909 (2012).

[23] Z. Jiao and N. Shikazono, J. Electrochem. Soc., 161(5), F577-F582 (2014).

[24] S. Hara, A. Ohi and N. Shikazono, J. Power Sources, 276, 105-112 (2015).

[25] A. R. Wazzan, J. Appl. Phys., 36, 3596-3599 (1965). 

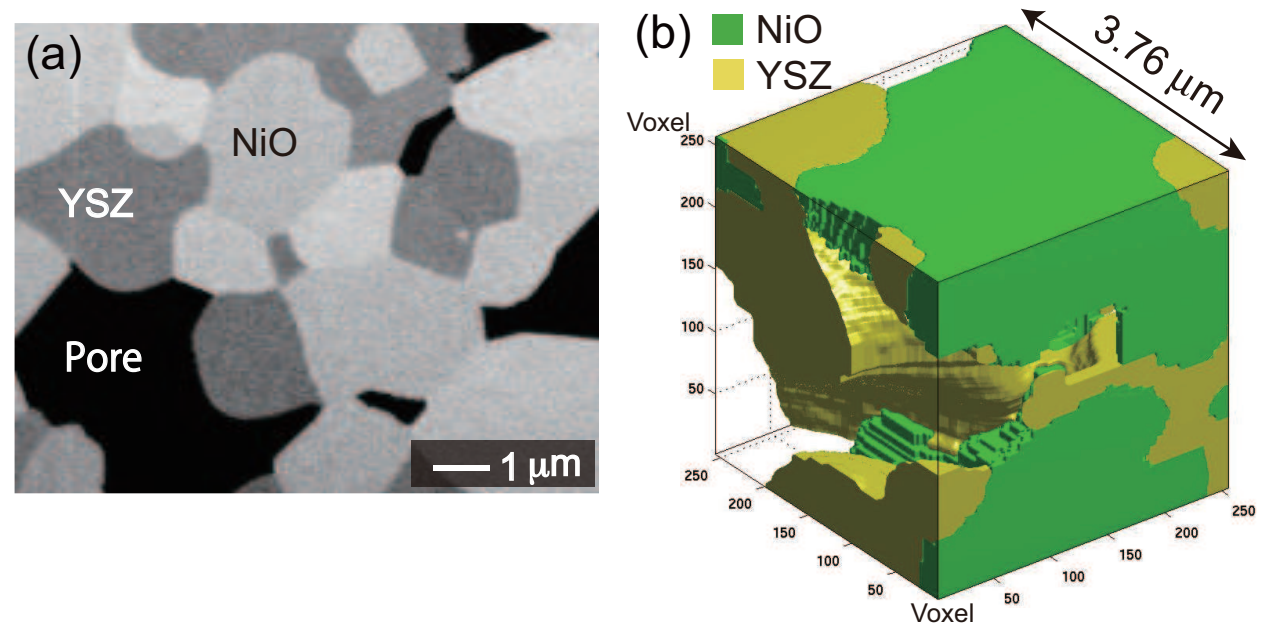

Figure 1: (a) 2D FIB-SEM image and (b) corresponding 3D reconstruction of composite NiO-YSZ anode before reduction. (Green: NiO Gray, yellow: YSZ).

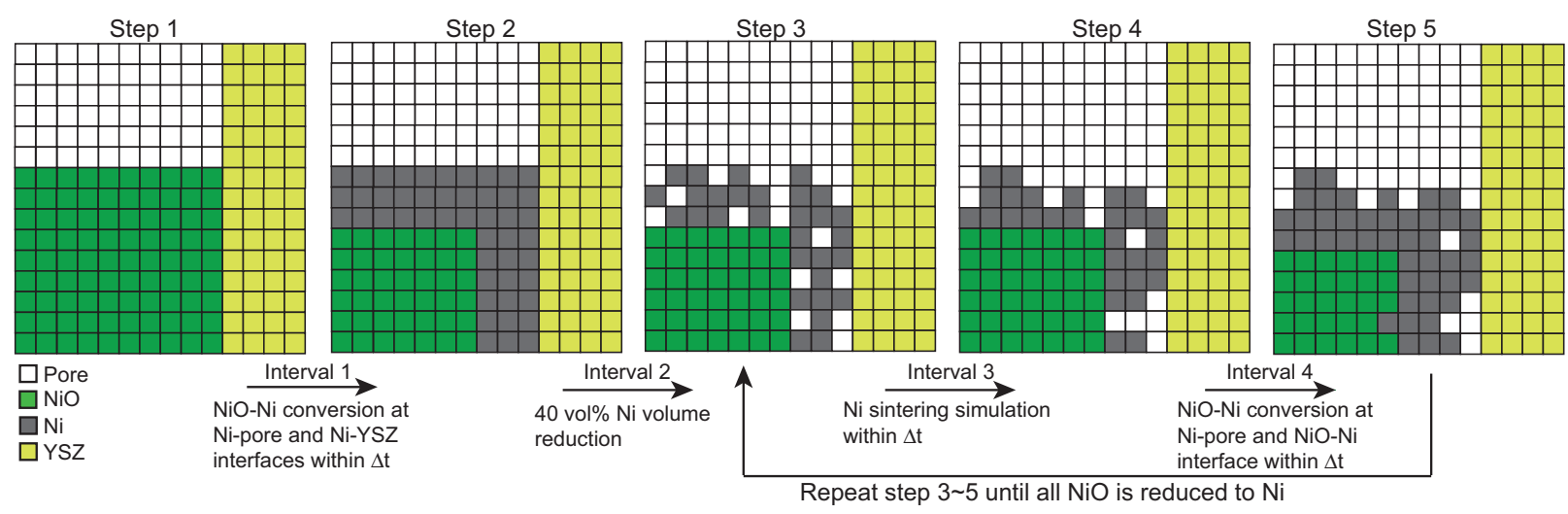

Figure 2: Process flow for the simulation of $\mathrm{NiO}$ reduction. 


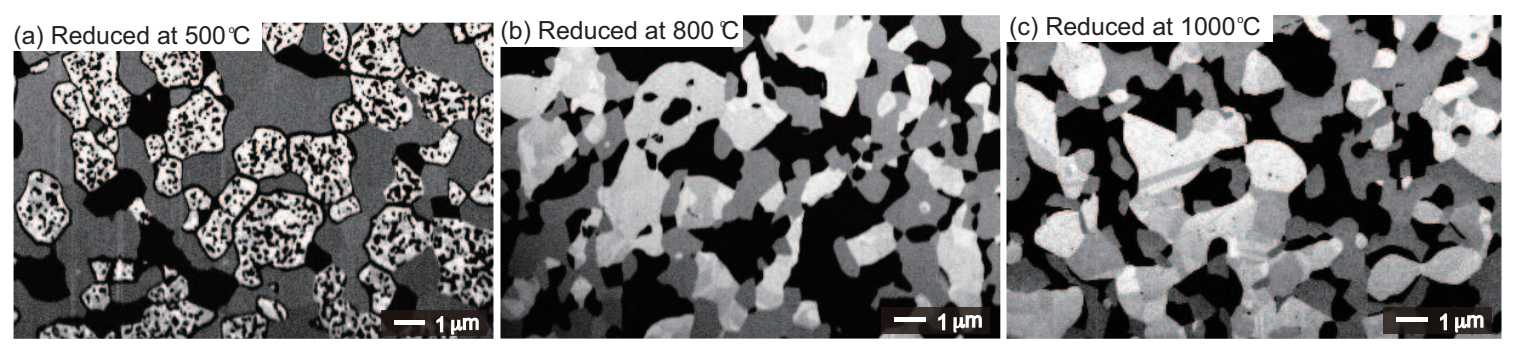

Figure 4: SEM images of the cross-sections of anodes reduced at (a) $500^{\circ} \mathrm{C}$, (b) $800^{\circ} \mathrm{C}$ and

(c) $1000^{\circ} \mathrm{C}$ in $5 \% \mathrm{H}_{2}$ hydrogen diluted by $\mathrm{N}_{2}$. White: Ni, gray: YSZ, and black: Pore. 

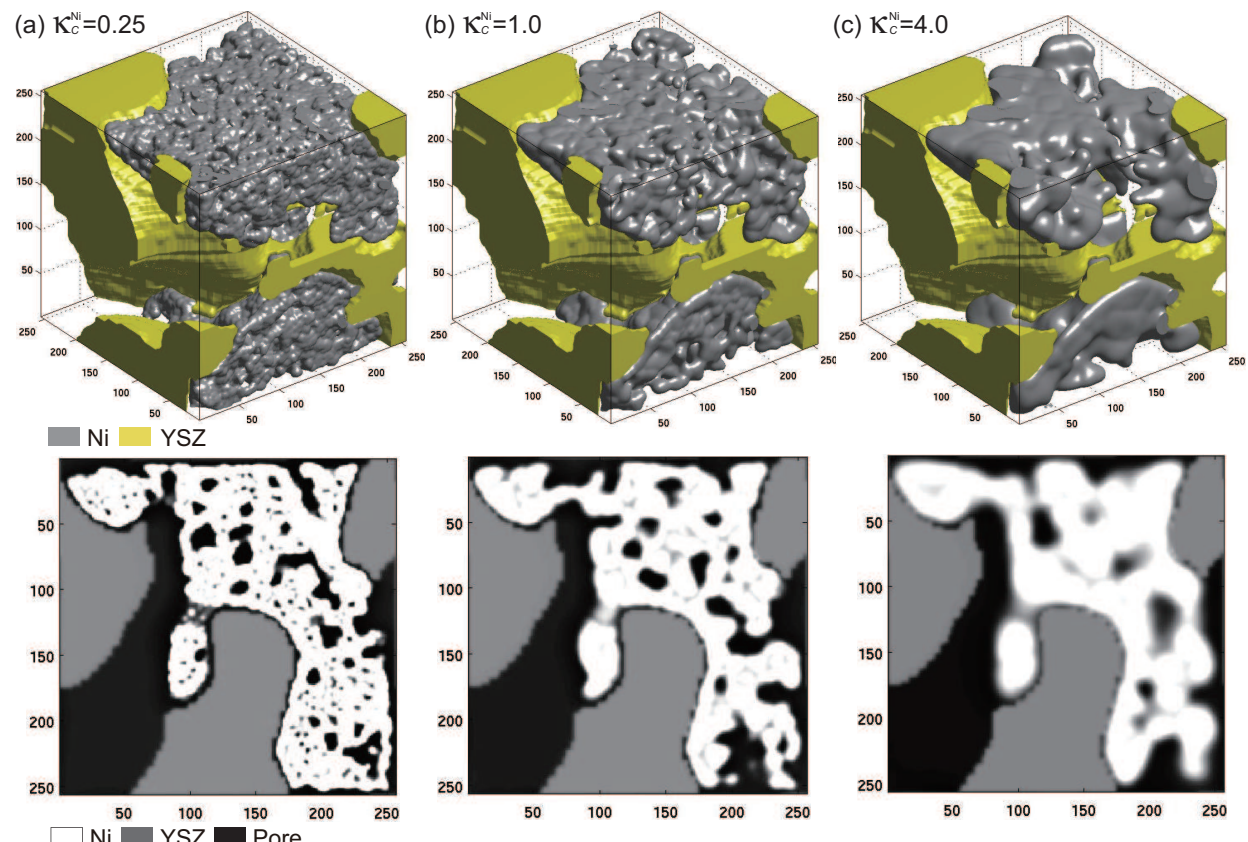

Figure 5: 3D model predictions and the corresponding cross-section 2D images of reduction process with different phase gradient energy coefficients. (a) $\kappa_{C}^{\mathrm{Ni}}=0.25$, (b) $\kappa_{C}^{\mathrm{Ni}}=1.0$ and (c) $\kappa_{C}^{\mathrm{Ni}}=4.0$ at $t^{*}=32$.
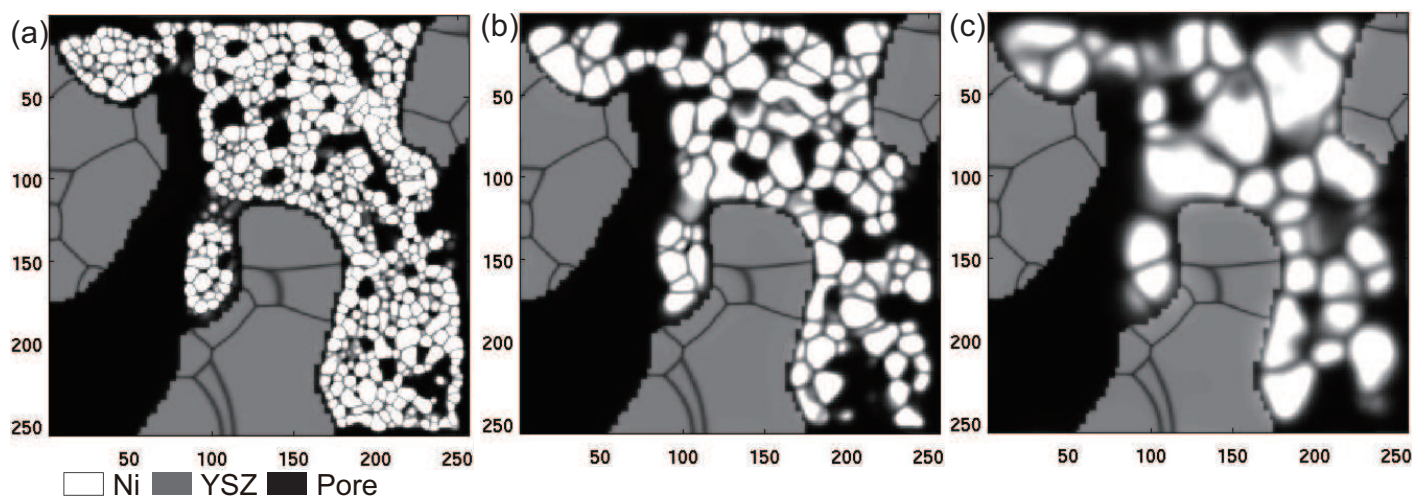

Figure 6: 2D cross-sectional images of anode crystal microstructure corresponding to Fig. 5. White: Ni, gray: YSZ, and black: Pore. 